\title{
Piezoelectric ceramic applications: micromixing in biology and medicine
}

\author{
Sajin Maria ${ }^{1}$, Craciunoiu Florea², Moisin Ana Maria ${ }^{3}$, \\ Dumitru Alina Iulia ${ }^{3}$, Petrescu Daniel ${ }^{1}$, Raluca Gavrila ${ }^{2}$, \\ Bunea Alina Cristina ${ }^{2}$ and Sajin Gheorghe Ioan ${ }^{2}$ \\ 1 University of Medicine "Carol Davila", Chair of Pathology, Bucharest \\ ${ }^{2}$ National Institute for Research and Development in Microtechnologies, Bucharest, \\ ${ }^{3}$ National Institute for Research and Development in Electrotechnics, ICPE-CA, Bucharest,
}

\section{Introduction}

Reducing the dimensions of macroscopic biological or chemical laboratories is advantageous, the small scale allowing the integration of various processes on one chip, analogous to integrated microelectronic circuitry. The microfluidic technology based on the "lab-on-a-chip" principle allows the usage of very small biological material quantities, decreases the quantity of reactives and waste and increases the speed in obtaining the results making use of automatization, integration, modularization and parallel processing (Southern, et al., 1999; Cai, et al., 2002). Such integration is prerequisite for a fully automated data management system covering all steps of a given chemical or biological process. Finally, the miniaturization results in enhanced precision by providing more homogenous reaction conditions in a shorter time (Pollack, et al., 1999; Hames \& Higgins, 1990).

Surface acoustic wave (SAW) devices as nano-pumps and micro-mixers used in microfluidic bio-medical applications are one of the uprising domains today. Surely, the conventional pumps cannot be used for the displacement of the very small liquid quantities on the substrate's surface. To move such little liquid quantities in a "lab on a chip", integrated nano-pumps on the substrate's surface, are used. Using a piezoelectric substrate as support, SAWs are generated by application of an alternative signal with a suitable frequency and amplitude to a system of interdigital transducers (IDT). SAWs are launched on the substrate's surface normally on the IDT lines and move like the water waves on the surface of a lake. This movement is used to move small drops of liquid on the substrate's surface.

Concerning the use of SAWs in micromixing applications, although the wavelengths are of the order of micrometers and wave amplitudes are of the order of nanometers, they are sufficient to produce fluidic nanocurrents inside the liquid droplets. These nanocurrents have chaotic movements that superimpose allowing mixing of their content. One of the applications of this microfluidic applications are "in situ" hybridization stations. In these stations, standard micro-meshes of DNA, proteins or other biological fluids are put in contact with a piezoceramic substrate supporting a SAW. Microagitation of the fluids during the incubation dramatically shortens the hybridization time (Toegl et al., 2003). 
However, biological fluids (biological media, cell suspensions, various solutions and some chemicals) may be very aggressive to the materials used in biomedical engineering. It is a less studied aspect of biocompatibility.

In this respect, two aspects were studied: (i) the influence of a piezoceramic substrate on a biological medium represented by a cell population and (ii) the influence of this biological medium (a cell suspension) and processing chemicals on this kind of substrate (possible surface damaging, roughness or porosity increase).

\section{Elements concerning fabrication technology of biocompatible piezoelectric ceramics}

The known materials with piezoelectric properties are potassium sodium tartrate $\left(\mathrm{NaKC}_{2} \mathrm{H}_{4} \mathrm{O}_{6} .4 \mathrm{H}_{2} \mathrm{O}\right)$ also known as Rochelle salt, barium titanate $\left(\mathrm{BaTiO}_{3}\right)$, lead titanate $\left(\mathrm{PbTiO}_{3}\right)$, lead zirconate titanate $\left(\mathrm{PbZr}_{1-\mathrm{x}} \mathrm{Ti}_{\mathrm{x}} \mathrm{O}_{3}\right)$, zinc oxide $(\mathrm{ZnO})$, aluminium nitrate $(\mathrm{AlN})$, etc. One of the most used piezoelectric ceramic is the lead zirconate titanate (PZT) (Jaffe et al. 1971). It presents excellent piezoelectric properties, high Curie temperature and high spontaneous polarization, properties that made it widely used in electrical applications. By using bulk PZT substrates, the working frequency is extended to about $20 \mathrm{MHz}$, limited by the thickness and porosity of the active piezoelectric element.

The modified PZT ceramic, doped with different elements, can be prepared through a classical technology (Setter, 2002) following a flow shortly presented below.

The active piezoelectric elements used as substrates in SAW micromixing components were elaborated in this technology in which, in the first stage, the ceramic powder is obtained and then, it is further processed into a bulk element through shaping, pressing and sintering processes. These two stages are complementary and constitute the technological flow in the conventional ceramic processing.

The processing developed in these two main stages is given in the table below:

\begin{tabular}{|c|c|c|c|}
\hline No. & Stages & Processing & Intermediary products \\
\hline \multirow[t]{6}{*}{1.} & \multirow{6}{*}{$\begin{array}{l}\text { Elaboration of the } \\
\text { ceramic powder }\end{array}$} & dosage & \multirow[t]{6}{*}{ Ceramic powder } \\
\hline & & homogenization & \\
\hline & & milling & \\
\hline & & calcination & \\
\hline & & milling & \\
\hline & & properties testing & \\
\hline \multirow[t]{7}{*}{2.} & \multirow{7}{*}{$\begin{array}{l}\text { Elaboration of bulk } \\
\text { ceramic }\end{array}$} & shaping & \multirow{7}{*}{$\begin{array}{l}\text { Ceramic plates - active } \\
\text { piezoelectric elements }\end{array}$} \\
\hline & & pressing & \\
\hline & & sintering & \\
\hline & & cutting/ lapping/polishing & \\
\hline & & electrical poling & \\
\hline & & $\begin{array}{l}\text { morphological/structural } \\
\text { investigation }\end{array}$ & \\
\hline & & properties testing & \\
\hline
\end{tabular}

Table 1. The main two stages in the conventional ceramic technology 
Each main stage ends with a specific control of the powder respectively of the bulk material. The main properties of the ceramics, as requested by the application, are: a prevailing perovskit type crystalline phase, high purity and homogeneity of the ceramic material, micronic dimension of the ceramic grains, high densification (that means the lowest possible porosity), fine superficial roughness of the ceramic plates and, last but not least, biocompatibility with the biologic medium to be handled.

These characteristics are achieved starting with the powder processing in the first stage of the technological flow. It is necessary to obtain fine granulated ceramic powder because, mainly the sintering process, contributes to the growth of the ceramic grains.

The apparent density of the bulk is determined both by the granulation of the ceramic powder and by the pressing conditions. For a granulation controlled ceramic powder, significant differences occur between the normal uniaxial pressing process, followed by sintering, and the hot pressing or isostatic pressing process. The roughness of the bulk surfaces, very important for the quality of the interdigital structures, is dependent on the ceramic granulation. The roughness of the surfaces is obtained by mechanical processing (grinding, lapping, polishing) and sometimes by chemical corrosion.

In order to get products with the requested characteristics, the development of the elementary processing has to be controlled and optimized. A schematic presentation of the technology used for the preparation of PZT ceramics is given in Fig.1. The following important facts can be extracted:

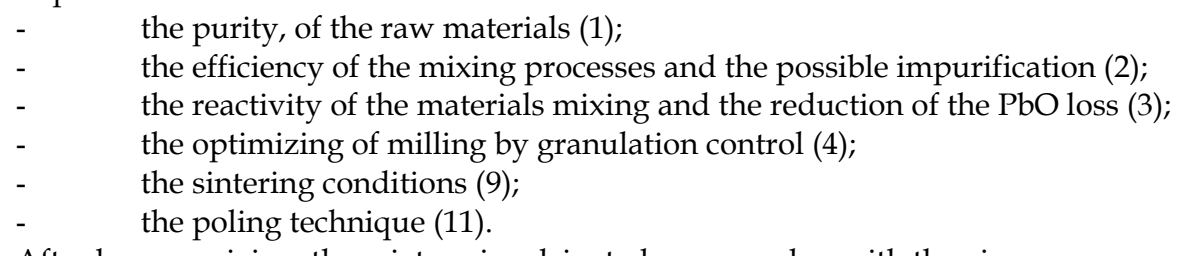

After homogenizing, the mixture is calcinated as a powder, with the aim:

a) of removing the residual water from the carbonates and the volatile impurities;

b) of obtaining the chemical reactions between the components (oxides and/ or carbonates) and to get the solid solution;

c) of diminishing the volume reduction, due to the reactions;

The calcination temperature must be high enough to facilitate the reactions and, in the same time, sufficiently low to enable the subsequent milling process. For the PZT system the temperature has to also be low to avoid the $\mathrm{PbO}$ evaporation. The temperature, duration and firing diagrams of the calcination have to be experimentally established for each situation.

The milling contributes to the material homogenization and to the compositional differences which appear after calcination. A milling to $1 \div 10 \mu \mathrm{m}$ grain dimension is recommended. Too large grains induce porosity and too fine grains determine colloidal properties of the powder which disturb the technological process.

The sintering conditions of the piezoelectric ceramics are determined experimentally, too. For PZT ceramics, sintering temperatures between $1100^{\circ} \mathrm{C}$ and $1300^{\circ} \mathrm{C}$ are recommended, and special methods have to be used to maintain the partial pressure of $\mathrm{PbO}$. 


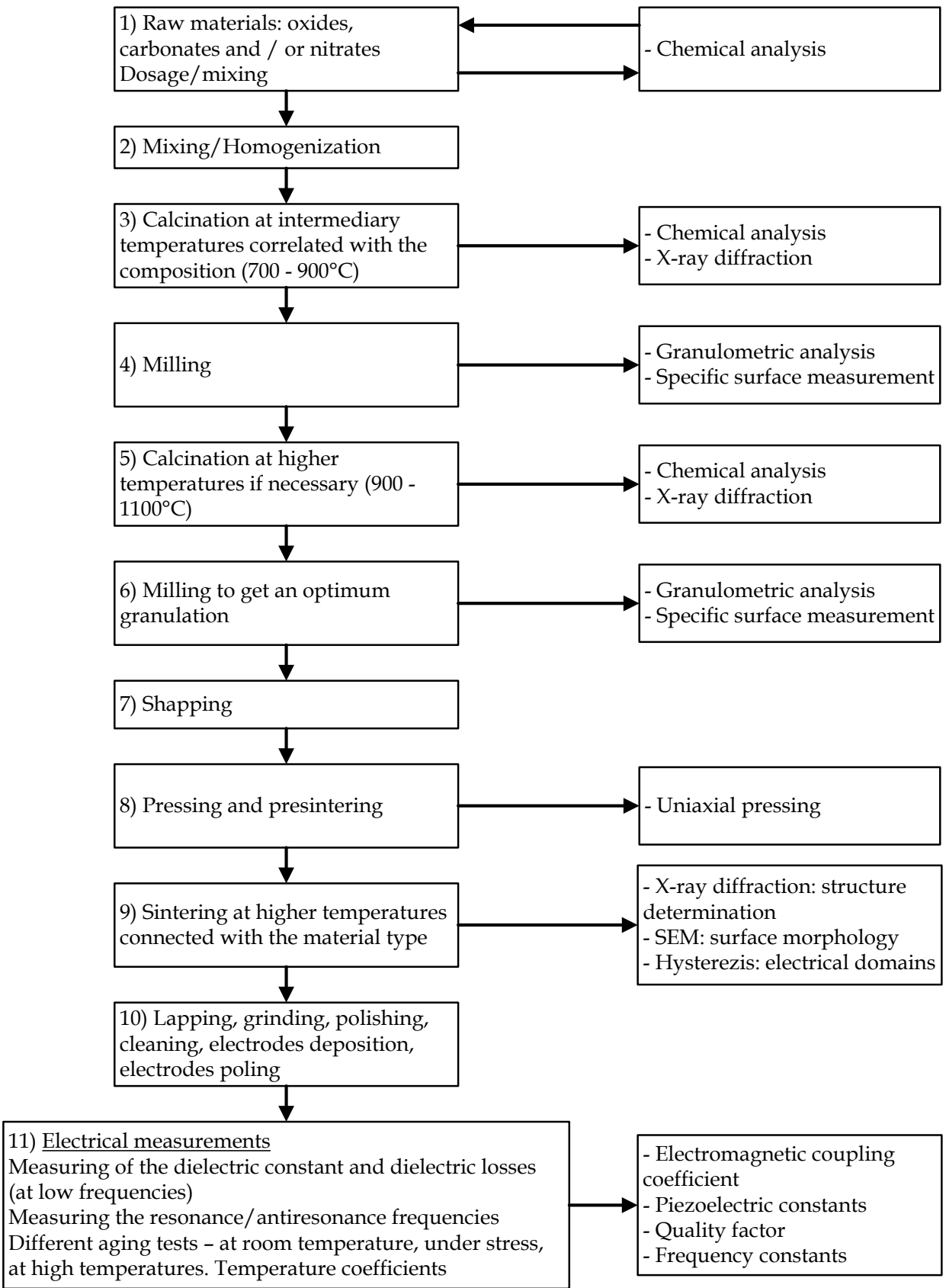

Fig. 1. A schematic presentation of the classical ceramic technology 
The active piezoelectric ceramic elements have different shapes and dimensions, and also smooth surfaces. High precision lapping machines are used with different abrasive materials such as aluminium oxide, silicium carbide or diamond powder.

The piezoceramic active elements are obtained by electrical poling, this process being specific for each application. It is important to get high remnant polarization values, thus obtaining high piezoelectric properties. There are different poling modes:

- transversal, for a rectangular plate, with $\mathrm{P} \perp \mathrm{V}$,

- radial, for a disc element, with $\mathrm{P} \perp \mathrm{V}$,

- longitudinal, with $\mathrm{P} \| \mathrm{V}$ for a cylindrical element,

- thickness, P $\|$ V for a disc element,

- $\quad$ shearing, for a rectangular plate element.

where $\mathrm{P}$ is the electrical poling vector and $\mathrm{V}$, the vibration vector. The corresponding coupling coefficients are $\mathrm{k}_{31}, \mathrm{k}_{\mathrm{p}}, \mathrm{k}_{33}, \mathrm{k}_{\mathrm{t}}$ si respectively $\mathrm{k}_{15}$.

For each composition it is necessary to determine the optimum poling parameters, avoiding the breakdown of the ceramic material determined by the porosity and different defects of the ceramic element (cracks, dislocations, vacancies or other defects at microscopic scale). The dielectric strength also depends on the thickness and shape of the ceramic samples.

The induced polarization into the ceramic sample depends on the poling duration, electrical field and working temperature. The applied electrical field, together with an increased temperature, accelerate the mobility and ordering of the dipoles. After poling, the measured piezoelectric properties give, indirectly, the value of the induced polarization. The most important parameter for the present application is the electromagnetic coupling coefficient, directly correlated to the remnant polarization. The evaluation of the polarization degree of the samples is made by measuring the fundamental resonance and antiresonance frequencies, and also the first harmonic, as well as the electrical admittance characteristics in correlation with the frequency. The resonance frequency corresponds to the maximum value of the admittance, the antiresonance frequency to its minimum value. By using these values one can compute the electromechanical coupling coefficients, the Poisson coefficient a.s.o.

The research focused on the technological variants able to produce submicronic and nanostructured piezoelectric materials. Experiments were carried out on different compositional variants and the results can be extended to other piezoelectric systems which are interesting for applications.

For the micromixing application, a piezoceramic powder with submicronic granulation was obtained, by using advanced milling processing (Kong et al., 2002). The obtained grain dimensions were submicronic, in the range $(500-1000 \mathrm{~nm})$, the small dimensions determining a densification of the ceramic bulk, the reduction of the surface roughness of the active ceramic elements and the altering of some properties, mainly the dielectric losses. A granulometric analysis of the ceramic powder was performed. Some results obtained on PZT-F are given in the histograms in Fig.2. The milling duration was respectively 1, 2 and 3 hours and ceramic grain dimensions under $0.5 \mu \mathrm{m}$ were obtained.

By increasing the milling duration one also observes the appearance of fine powder agglomerations. Therefore it is necessary to find an optimum for the milling conditions in order to reduce these agglomerations. The values obtained for the specific surface are given in Table 2. 
This ceramic powder was used to get bulk active piezoceramic elements. Different thermal treatments were studied to diminish the size increase of the grains in order to finally get uniform and fine grained materials.

\begin{tabular}{|c|c|c|c|}
\hline Milling & Attritor Mill/ 1h & Attritor Mill/ 2h & Attritor Mill/ 3h \\
\hline $\begin{array}{c}\text { Area of the specific } \\
\text { surface }\left[\mathrm{m}^{2} / \mathrm{cc}\right]\end{array}$ & 23.44 & 20.88 & 17.49 \\
\hline
\end{tabular}

Table 2. The area of the specific surface for a PZT-F powder for different milling durations.

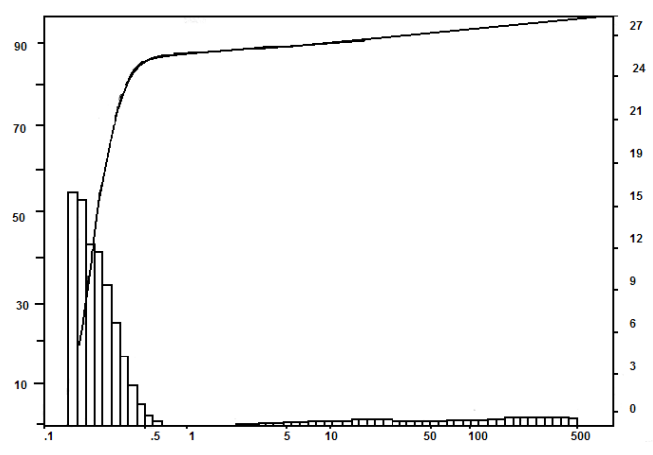

(a) Milling duration: $1 \mathrm{~h}$

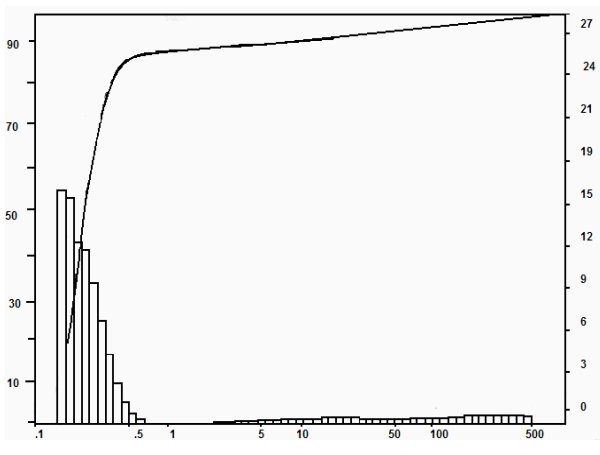

(b) Milling duration: $2 \mathrm{~h}$

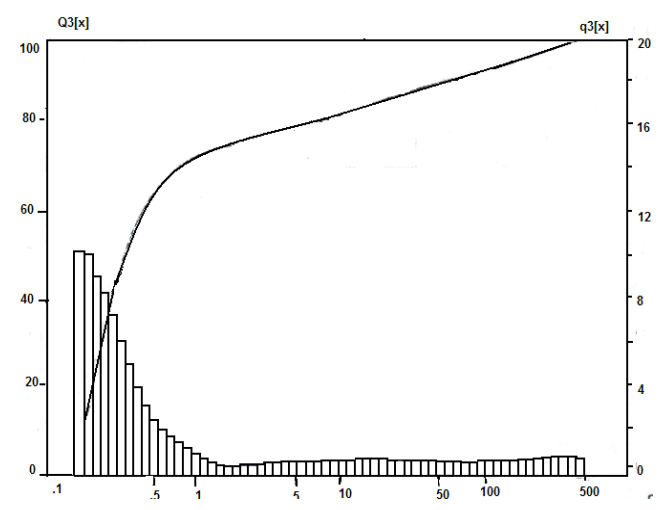

(c) Milling duration: $3 \mathrm{~h}$

Fig. 2. The distribution of the dimensions of the ceramic grains after milling in an Attritor mill.

The influence of the thermal treatment on the grain dimensions was evidenced by microscopic analysis. Thus, in Fig. 3 the results obtained for a ceramic material of the PMNPT system, sintered three hours at $1000^{\circ} \mathrm{C}, 1050{ }^{\circ} \mathrm{C}$ and respectively $1100{ }^{\circ} \mathrm{C}$, are presented (Blank D.H.A. et al., 2005; Moisin et al., 2006). 


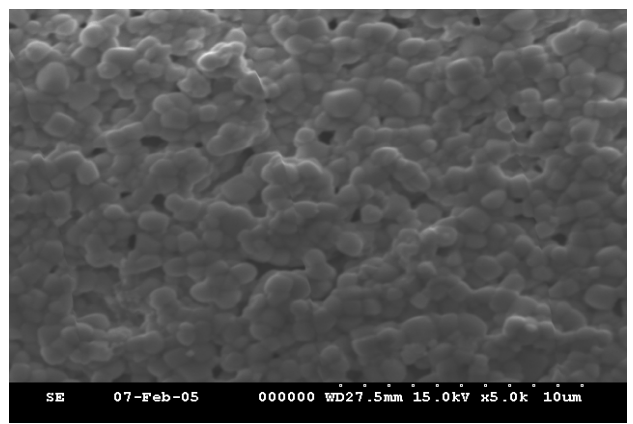

(a)

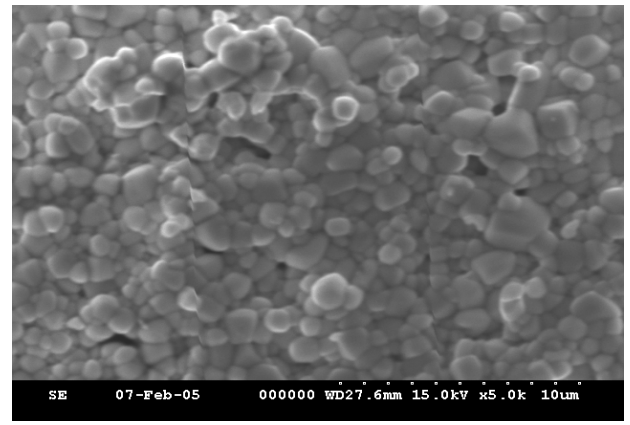

(b)

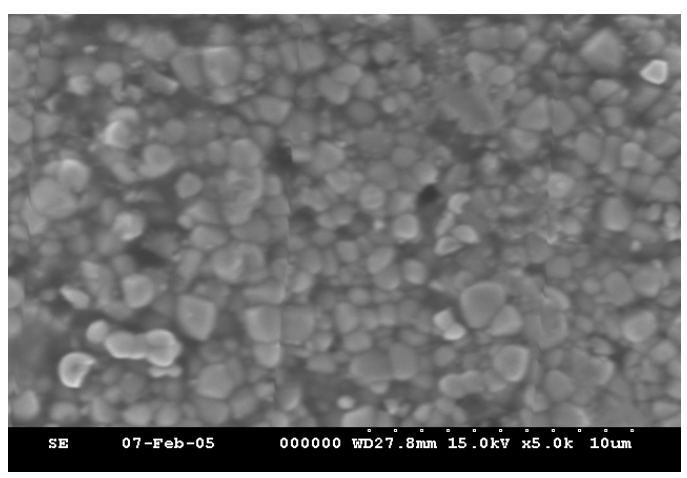

(c)

Fig. 3. SEM images obtained for PMN-PT sintered at $1000^{\circ} \mathrm{C} / 3 \mathrm{~h}$ (a), $1050^{\circ} \mathrm{C} / 3 \mathrm{~h}$ (b), $11000^{\circ} \mathrm{C} / 3 \mathrm{~h}(\mathrm{c})$

During the sintering process, the crystalline structure is fulfilled, in this example a prevailing perovskit type structure was obtained. In the same time an increase of the dimension of the ceramic grains takes place. In the images obtained through scanning electronic microscopy (SEM), at the same magnification $(5.000 \mathrm{X})$ one can observe the appearance of ceramic grains having a mean dimension smaller than $1 \mu \mathrm{m}$.

\section{SAW resonators for use in micromixing applications}

\subsection{Interdigital transducers (IDT) for SAW generation}

In this chapter, only some elements concerning the interdigital transducers as elements of SAW resonators will be presented. More complete data may be found in literature as, for instance, in (Morgan, 2007).

In order to convert an electrical signal in a surface acoustic wave structures consisting of alternating conducting segments deposited on the surface of a piezoelectric material are used. They are named InterDigital Transducers (IDT) and can be seen in Fig.4. 


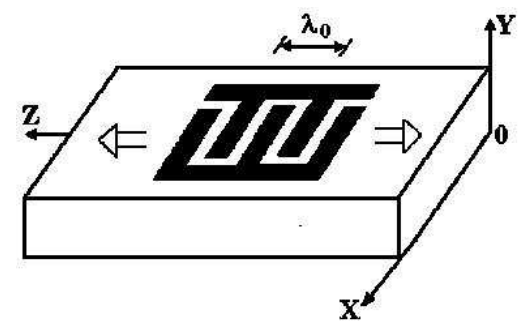

Fig. 4. IDT structure on a piezoceramic substrate

By applying an electrical sinusoidal signal to the interdigital transducer set as in Fig.4, a distribution of electric field components, as in Fig.5, results in the subjacent piezoelectric material.

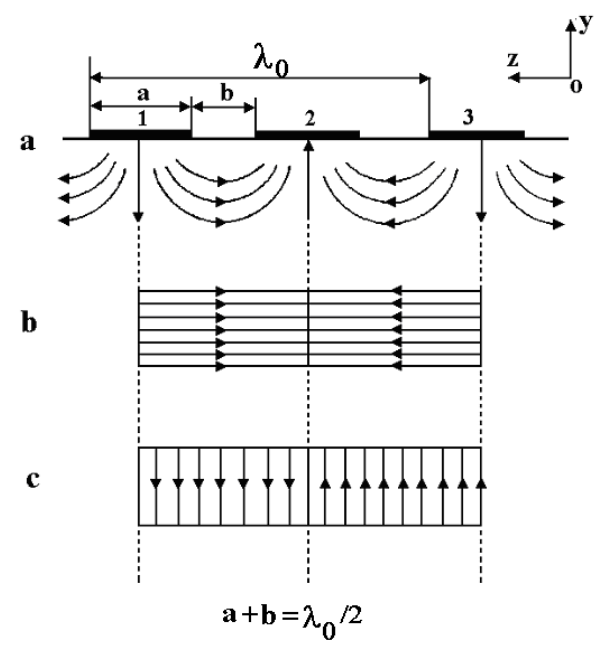

Fig. 5. Electric field distribution induced by an interdigital transducer in a piezoelectric material:

a) Realistic aspect of electric field lines;

b) Longitudinal approximation;

c) Transversal approximation.

Due to the piezoelectricity of the substrate, mechanical deformations are generated which generate Rayleigh surface waves. These waves propagate along the Oz axis. The surface waves produced by the neighbouring transducer are added in-phase if the periodicity of the interdigital structure is equal to half the wavelength $\lambda_{0} / 2$ at the frequency $f_{0}$. This means:

$$
a+b=\frac{\lambda_{0}}{2}
$$


The wave generated by the semi-section between segments 1 and 2 (see the figure) which propagates in the negative direction of the $\mathrm{Oz}$ axis will be proportional with $\sin \frac{2 \Pi}{\lambda_{0}}(z+v t)$, where $\mathrm{z}$ is the distance on the $\mathrm{Oz}$ axis, $\mathrm{v}$ is the velocity of the wave and $\mathrm{t}$ is the time travelled.

If the condition (1) is fulfilled, this wave arrives under the semi-section between segments 2 and 3 with a phase shift expressed by:

$$
-\frac{2 \Pi}{\lambda_{0}}(a+b)=-\Pi
$$

As a result, this wave will be added to the wave generated by segments 2 and 3 which have a $\pi / 2$ phase shift. The electric - elastic (and reverse) conversion induced by the interdigital structure is a selective conversion and the transfer characteristic for a periodic transducer with equal segments (uniform covering) is proportional to:

$$
\left[\frac{\sin \left(\mathrm{N} \Pi \frac{\mathrm{f}-\mathrm{f}_{0}}{\mathrm{f}_{0}}\right)}{\mathrm{N} \Pi \frac{\mathrm{f}-\mathrm{f}_{0}}{\mathrm{f}_{0}}}\right]
$$

where $\mathrm{N}$ is the number of the sections of the transducer and $f_{0}$ is the synchronic frequency. The synchronic frequency determines the periodicity of the IDT structure. For example, for a frequency $\mathrm{f}_{0}=300 \mathrm{MHz}$ on a lithium substrate $(\mathrm{v}=3488 \mathrm{~m} / \mathrm{s})$ results $\lambda_{0}=\frac{\mathrm{v}}{\mathrm{f}_{0}}=11.6 \mu \mathrm{m}$ that means a conductor width of $2.9 \mu \mathrm{m}$.

Conversion attenuation electric - elastic (and reverse) is defined as:

$$
a_{C}(d B)=-10 \log \frac{P_{1}}{P_{2}}
$$

where $P_{1}$ is the active power at the electrical input of the transducer and $P_{2}$ is the active power at the elastic output.

\subsection{IDT fabrication and results concerning SAW resonant frequency}

The SAW micro-mixer structures were processed (Sajin et al., 2005) on a piezoceramic substituted $\mathrm{Pb}(\mathrm{TiZr}) \mathrm{O}_{3}$ material known as PZT ceramic. The exact formula of this substituted ceramic was $\mathrm{Pb}_{0.92} \mathrm{Nd}_{0.08}\left[\left(\mathrm{Ti}_{0.53} \mathrm{Zr}_{0.47}\right)\right] \mathrm{O}_{3}$. The ceramic wafer dimensions were: diameter $\mathrm{D}=40 \mathrm{~mm}$ and thickness $\mathrm{T}=0.5 \mathrm{~mm}$.

For the micromixing applications, the resonator structure was designed for a frequency $\mathrm{f}_{0}=10 \mathrm{MHz}$. The wavelength, in this case, is $\lambda=48 \mu \mathrm{m}$ allowing IDT lines with a width $\mathrm{w}=12 \mu \mathrm{m}$. The distance between two IDT lines was, also, $12 \mu \mathrm{m}$. 
Two such structures obtained by a suitable photolithographic process on the same piezoceramic wafer are shown in Fig.6 (a) where (a) is the metallization not removed from the ceramic disk and (b) are the interdigital transducers (IDT) detailed in Fig.6 (b). The micromixing zone is (c) and the ceramic surface of this zone will be the subject of further biocompatibility experiments.

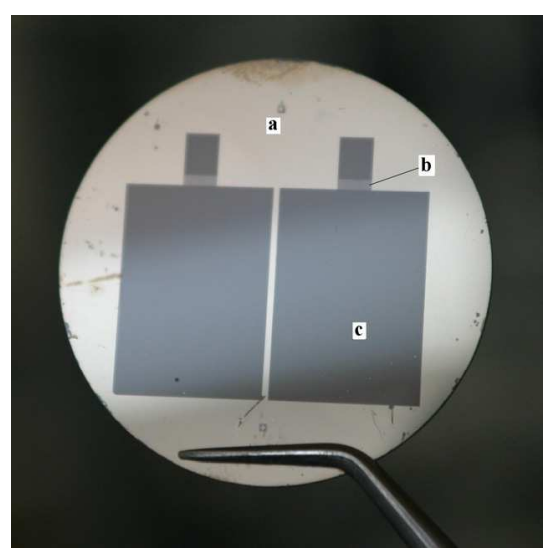

(a)

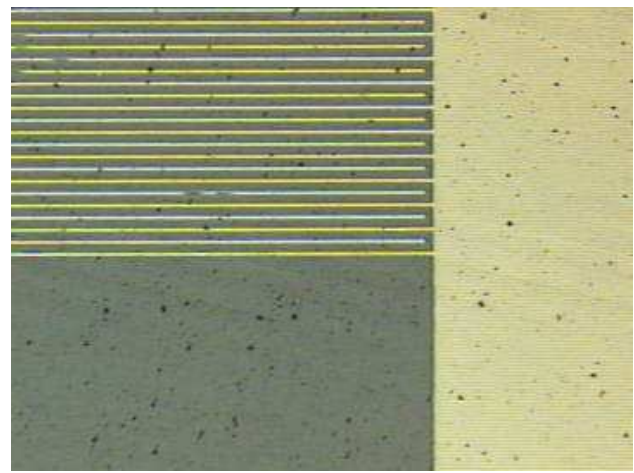

(b)

Fig. 6. SAW micro-mixer structure.

(a) - Two structures on a ceramic wafer; (b) - IDT structure; (c) - The micromixing zone.

The IDT system launches surface acoustic waves (SAW) in region (c) of the structure which is the active mixing surface. There are two identical structures on the shown ceramic wafer. In order to be used as micromixers, these structures will be separated by an adequate diamond cutting operation. Subsequently, each of them will be mounted in a suitable mechanical and electrical assembly in order to be used as a mixing device.

In order to verify the resonator functionality, the resonance frequency is measured. In this respect, the active structure of the micromixing device comprising the IDT and the mixing surface (see Fig.7) is cut out and mounted in a special test fixture especially conceived for this measurement. The measuring setup is presented in Fig.8 while the SAW resonator mounted on the test fixture is shown in Fig.7.

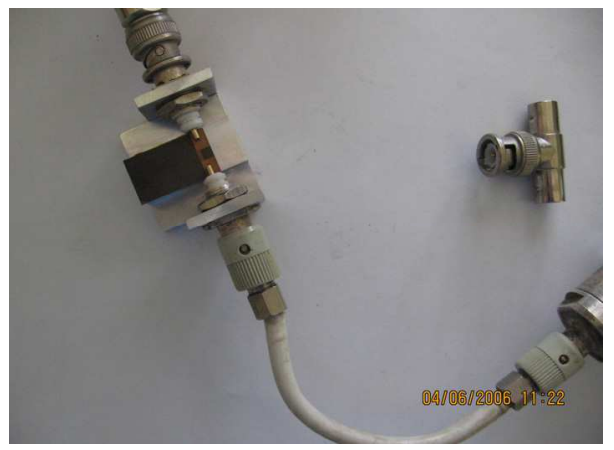

Fig. 7. The active structure of the micromixing device mounted on the test fixture 


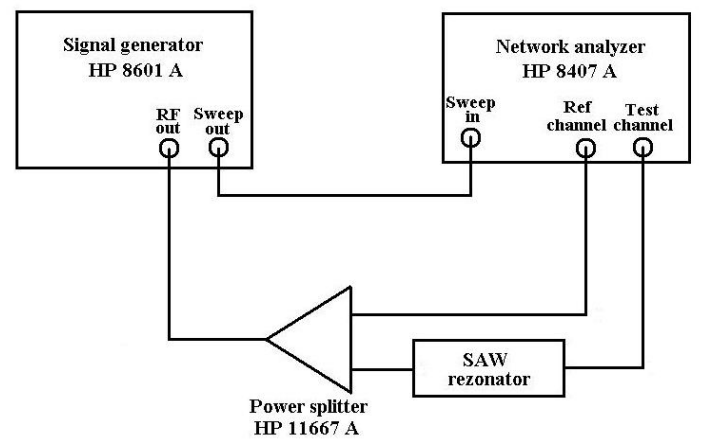

Fig. 8. Measuring setup for the SAW resonator

The measurement results on the SAW launching capabilities comprising resonant frequency and $S_{21}$ parameter for 2 devices are presented in Fig.9 (a) - (b).

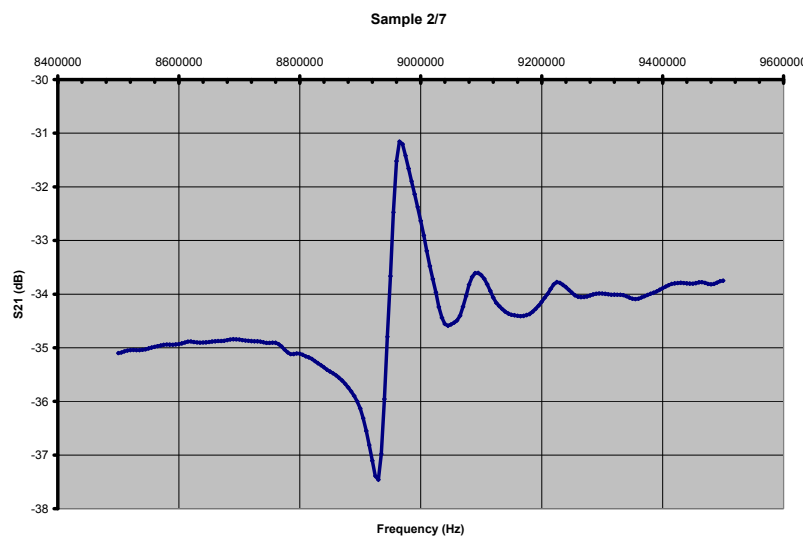

(a)

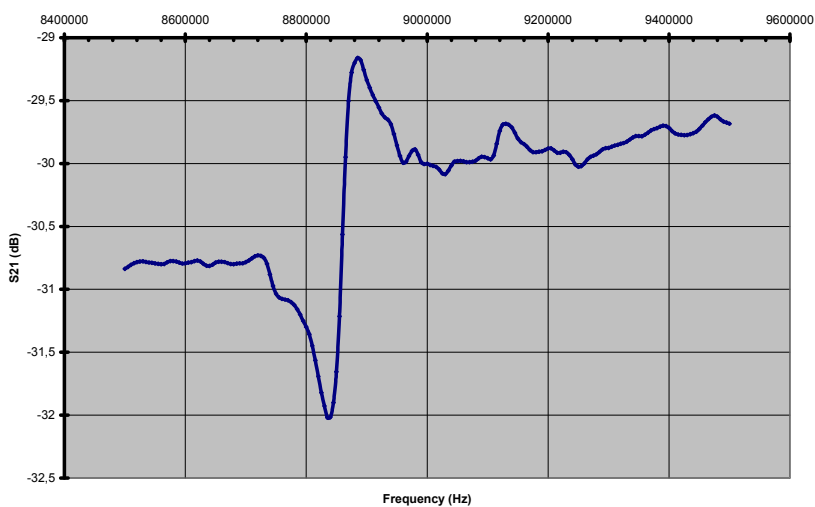

(b)

Fig. 9. (a) and (b). Resonant frequencies for two SAW structures to be used in micromixers. 
The resonant frequency is about. $8.85 \mathrm{MHz}$. The frequency dispersion is due to limited precision of the metallic lines forming the IDT. Indeed, as it was previously stated, the roughness of the ceramic substrate is of prime importance, as a rough surface limits the possibility to obtain the necessary narrow and long metallic lines. Two different illustrative cases are exemplified in Figs. $10-11$ and Figs. 12 - 13 respectively. The atomic force microscopy (AFM) images in Fig. 10, with scan area sizes varying from $20 \mu \mathrm{m}$ to $5 \mu \mathrm{m}$, depict the surface roughness of one of the substrates. Pits of about 6-8 $\mu \mathrm{m}$ in size could be noticed in the substrate topography in this case.

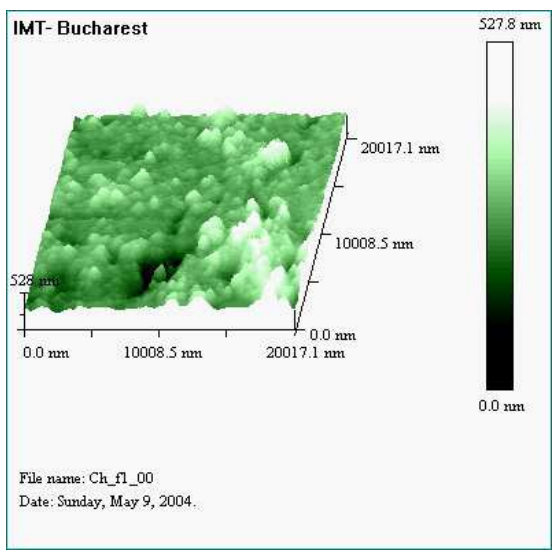

(a)

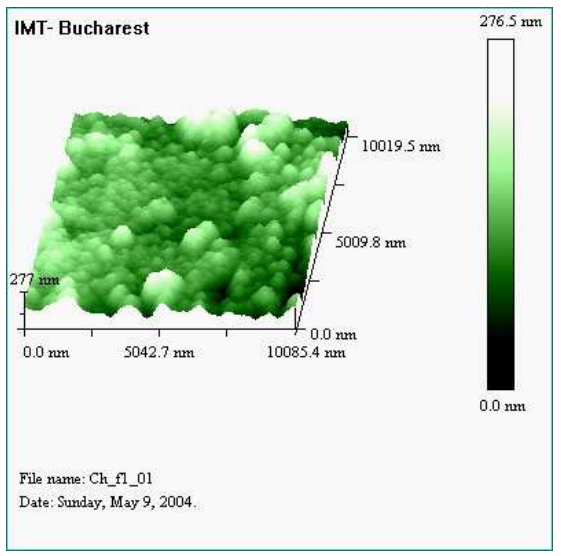

(b)

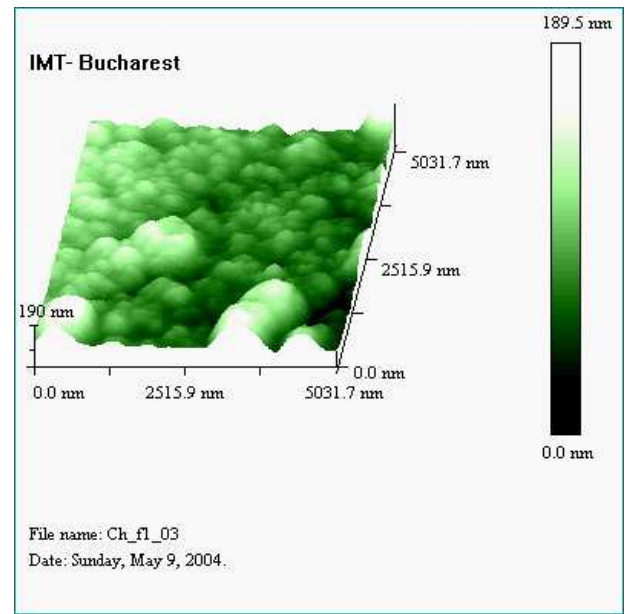

(c)

Fig. 10. Surface roughness for one of the used piezoelectric ceramics. Scan area size is respectively:
(a) $20 \mu \mathrm{m}$
(b) $\quad 10 \mu \mathrm{m}$
(c) $5 \mu \mathrm{m}$ 

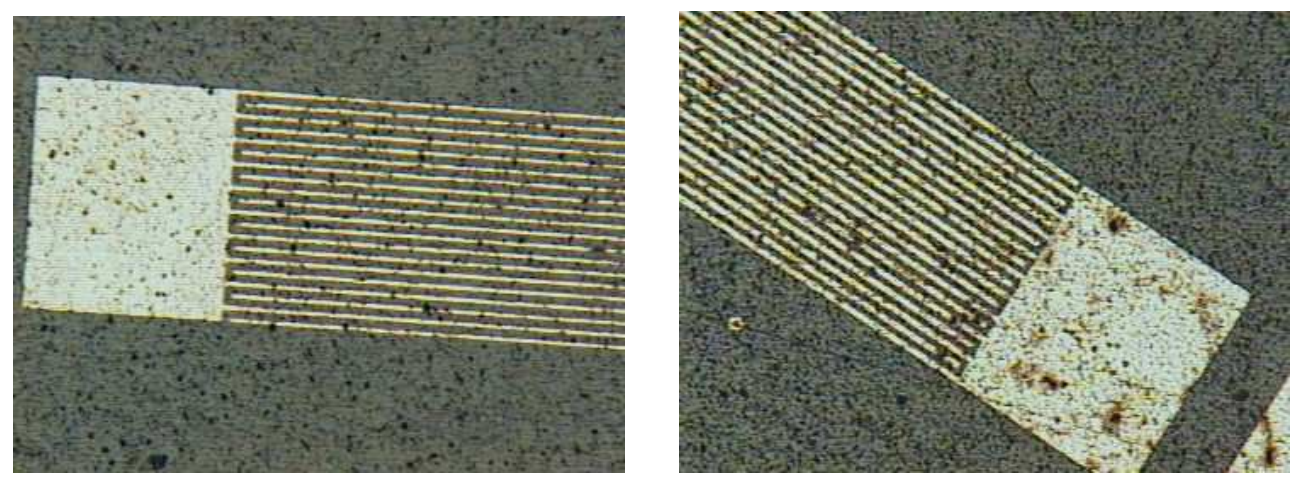

Fig. 11. Interdigital transducers obtained on the ceramic surface with the roughness like in Fig.10.

In this case the ceramic substrate was too rough to allow obtaining metallic lines accurate enough for IDT applications. This is visible in the IDT structures presented in Fig.11. For comparative purposes, remember that the widths of the metallic lines as well as the gap between two lines are $12 \mu \mathrm{m}$.

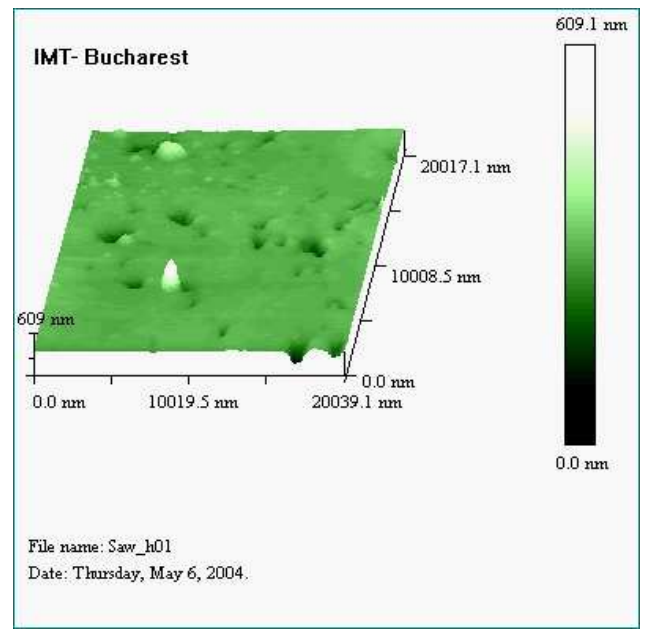

(a)

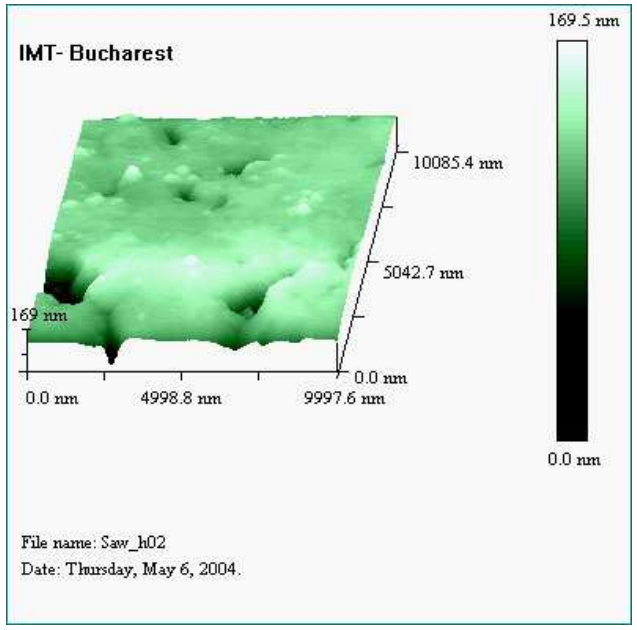

(b) 


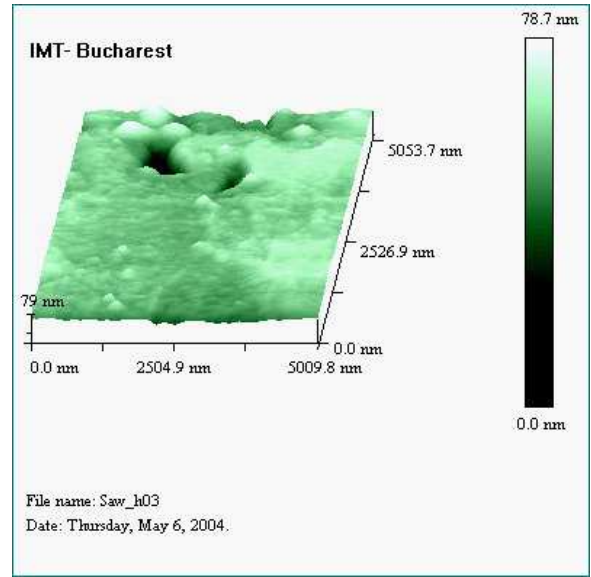

(c)

Fig. 12. Surface roughness of the second piezoelectric ceramic. Resolutions were, respectively:
(a) $20 \mu \mathrm{m}$
(b) $\quad 10 \mu \mathrm{m}$
(c) $5 \mu \mathrm{m}$

IDT lines obtained on this ceramic surface are shown in Fig.13. In this case, the better quality of the ceramic surface allowed a much accurate definition of the IDT lines obtained with the same technology as in the previous case (for comparison see Fig.11). The width of the metallic lines in Fig.13 (measured by optical microscopy) is $\cong 15 \mu \mathrm{m}$ and the space between two adjacent lines is $12-13 \mu \mathrm{m}$.
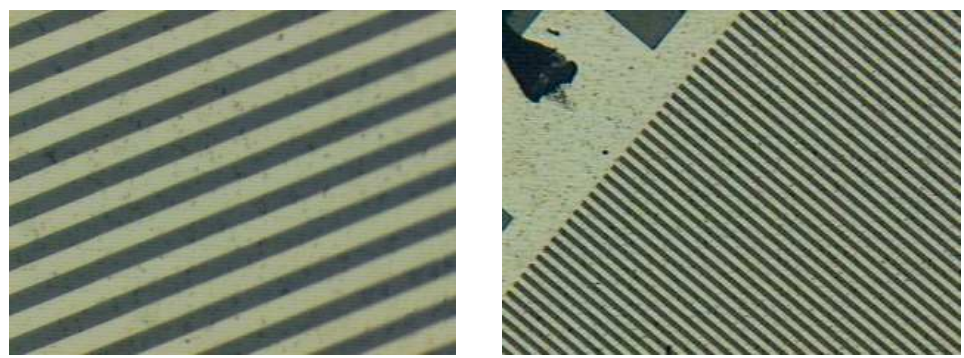

Fig. 13. IDT lines on piezoelectric ceramic with the surface roughness shown in Fig. 12.

The measurements of the surface roughness in both cases (Fig.10 and Fig.12) were made using an atomic force microscope (AFM).

\subsection{Construction and use of the micromixing device}

Finally, in order to handle it in the micromixing device, the piezoelectric ceramic wafer carrying the SAW resonator is glued on a laboratory glass slide. Inside the box of the micromixing device there is a space shaped to support a glass slide with the standard dimmensions $76 \times 26 \mathrm{~mm}^{2}$ used in the laboratory medical techniques. Athwart of this slide another slide is placed carrying the piezoelectric ceramic wafer. The whole micromixing device is 
presented in Fig.14 (a) ... (c) where Fig.14 (a) shows the glass slide carrying the SAW resonator, Fig. 14 (b) shows the micromixer with the active mixing element (ceramic wafer carrying the SAW resonator) in working position and Fig.14 (c) shows the assembled micromixer.
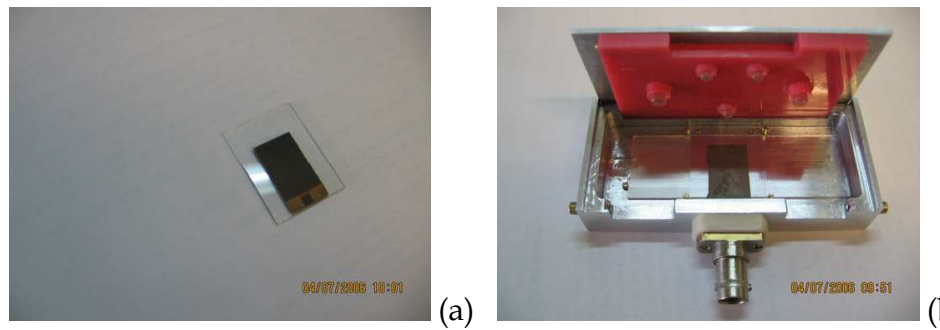

(b)

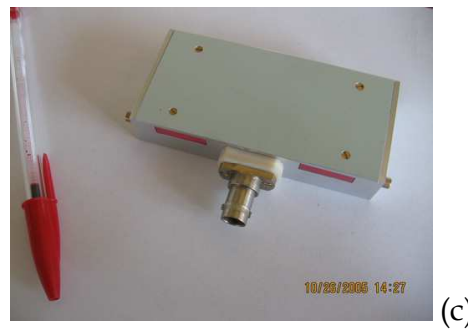

Fig. 14. (a) - The glass slide carrying the SAW resonator;

(b) - The micromixer with the active mixing element in working position;

(c) - The assembled micromixer

The alternative current is supplied to the mixing structure via a BNC connector and a system of elastic contacts inside the mixing box.

\subsection{Experimental results}

A micromixing experiment involves the following stages:

- Small drops of the substances to be mixed are placed on the glass slide in a chessboard arrangement. These droplets are placed only on the surface of the slide which will be covered by the mixing surface of the SAW resonator - zone (c) in Fig.6.

- The glass slide is inserted in the micromixer box with the droplets upward.

- The glass slide having the SAW resonator attached is placed on the glass slide supporting the substance droplets in such a manner that the piezoelectric wafer is in contact with the droplets of substances to be mixed. Although the mixing box is provided with guiding elements for a perfect placement of the SAW resonator, the operation will be undergone with care.

- The distance between the glass slide and the SAW wafer mixing surface is $50 \mu \mathrm{m}$, obtained by careful mechanical processing of the mixing box. This distance can be changed between $75 \mu \mathrm{m}$ and $20 \mu \mathrm{m}$.

- The lid of the mixing box is closed and the alternative signal with a frequency of $8.85 \mathrm{MHz}$ is applied to the SAW interdigital transducers through a coaxial cable fitted with a BNC connector. Application of the alternative signal to the IDT launches the surface acoustic waves that propagate on the piezoelectric ceramic wafer surface. These surface acoustic waves are efficiently absorbed by the fluids placed on the glass slide inducing the mixing process. 


\section{Study of the Bio-compatibility Between Piezoceramic Material and Biologic Cell Suspension}

In an attempt to use such a ceramic as substrate for a microfluidic surface acoustic waves (SAW) micro-mixer, the compatibility between a PZT substituted piezoceramic and a biological cell suspension was studied (Sajin et al., 2006). Two aspects were studied: (i) the influence of this kind of substrate on the development of a cell population and (ii) the influence of the cell suspension on the piezoceramic substrate.

\subsection{Methods}

First, the ceramic wafer was mirror polished on one face (the active face). Then, the wafer was successively washed with tap water, deionized water and sterile water, in order to remove all the remaining dust from the polishing process. Finally, the surface of such a prepared wafer was analyzed by optical microscopy and by atomic force microscopy (AFM) in order to estimate the roughness.

As biological medium a suspension of DC3F cells were used (pulmonary fibroblasts of Chinese hamsters) in D-MEM buffered with PBS, in a concentration of $5 \times 10^{5}$ cells placed in three $50 \mathrm{~mm}$ diameter Petri dishes.

The experimental ceramic wafer was put in a Petri dish containing the cell suspension. Two other Petri dishes containing the same biological medium but without a ceramic wafer were kept as controls. All Petri dishes were maintained at $370 \mathrm{C}$ in $5 \% \mathrm{CO}_{2}$ atmosphere and were observed daily for 4 days, in order to acknowledge the cell population development. Fig.15 shows the piezoelectric ceramic wafer in the Petri dish containing the biologic medium.

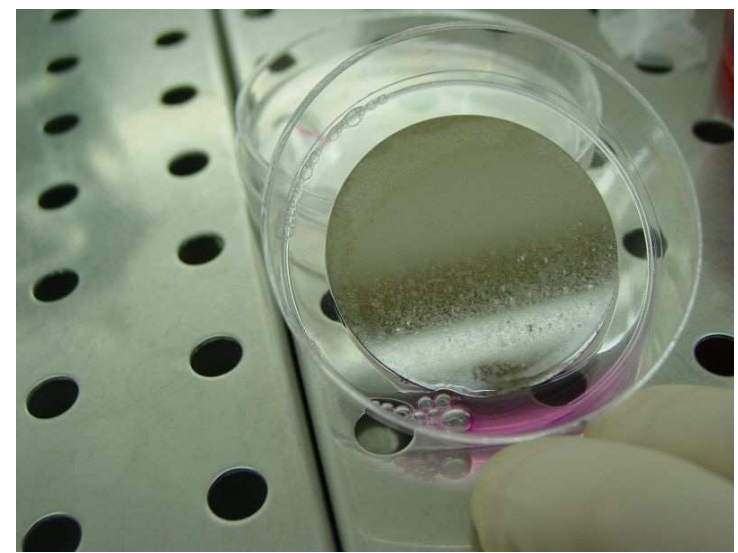

Fig. 15. Petri dish containing the ceramic wafer immersed in the cellular culture.

\subsection{Influence of the piezoelectric ceramic substrate on biological fluids}

The Figs.16 - 19 showing the development of cell cultures in experimental and in control Petri dishes were taken on the $3^{\text {rd }}$ day of the experiment.

In Fig.16 (a) and (b) one may see, at the optical microscope, that in the control Petri dishes the cells are attached on the dish bottom and walls. They form a continuous cellular layer and the color of the culture medium is orange. 


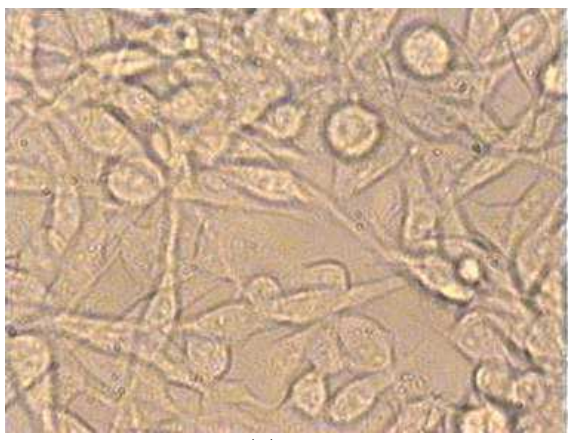

(a)

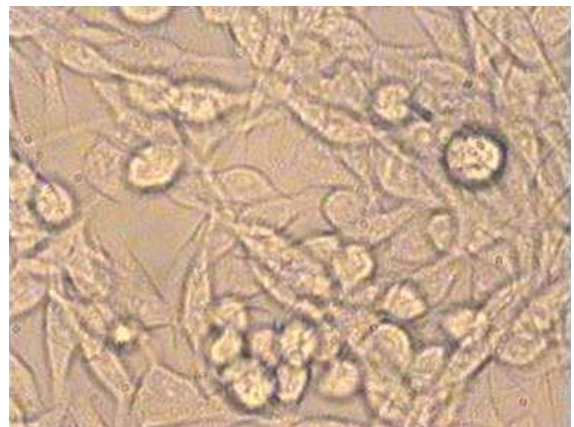

(b)

Fig. 16. (a) and (b). Continuous cellular layer in two locations in the control Petri dishes on the 3 rd day of the experiment. Phase contrast microscopy $100 \times$.

Fig. 17. (a), (b), (c) and (d) show the situation in the experimental Petri dish containing the ceramic wafer at the same time, on the $3^{\text {rd }}$ day.

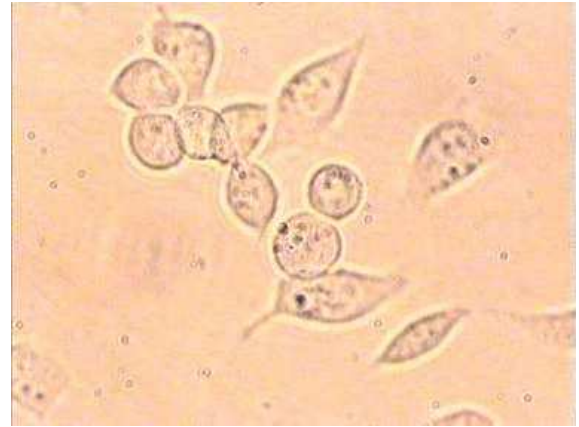

(a)

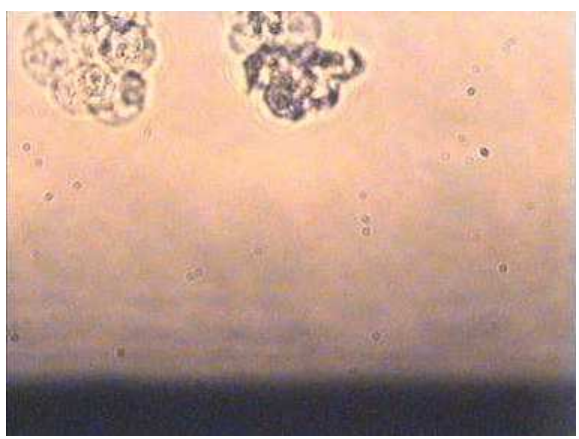

(c)

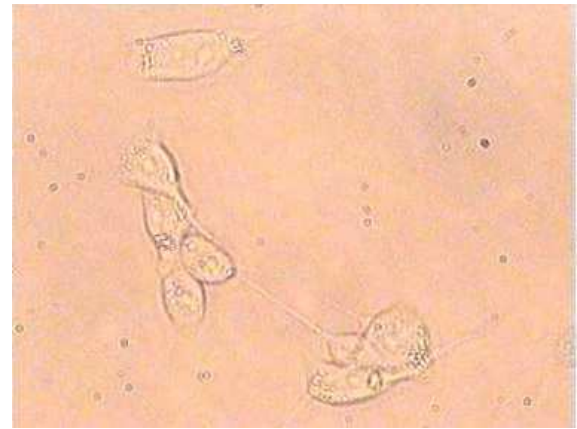

(b)

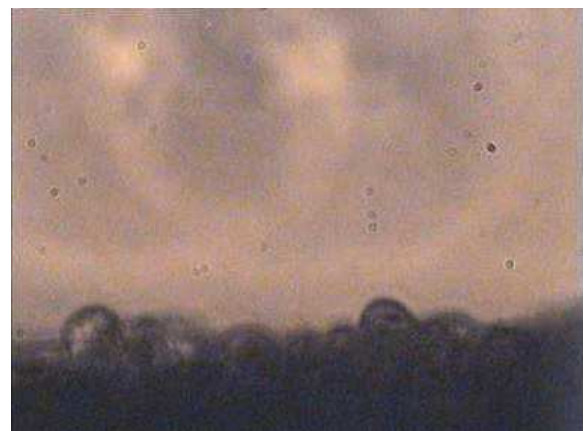

(d)

Fig. 17. (a) and (b). Groups of viable cells floating in suspension in two locations of the reference Petri dishes on the $3^{\text {rd }}$ day of the experiment. Phase contrast microscopy $100 \times$.

(c) and (d). Clusters of dead cells in two locations on the Petri dish containing the piezoceramic wafer, on the $3^{\text {rd }}$ day. Phase contrast microscopy $40 \times$. 
One may see, in Figs.17 (a) and (b) groups of viable cells floating in suspension. In Fig.17 (c) groups of dead cells are visible floating in suspension near the ceramic wafer and in Fig.17 (d) a cluster of dead cells are attached to the edge of the PZT piezoceramic wafer. Live cells are not yet attached to the ceramic wafer and the culture medium is pink.

In the $4^{\text {th }}$ day the experiment was stopped and the ceramic wafer was washed in HBSS and fixed in glutaraldehide 25\%. The result is visible in Fig.18 (a) and (b).

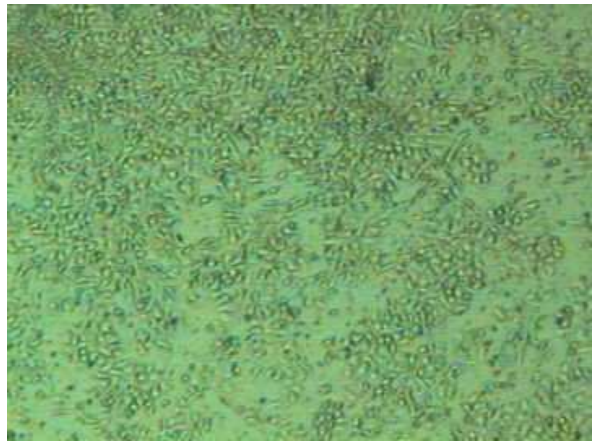

(a)

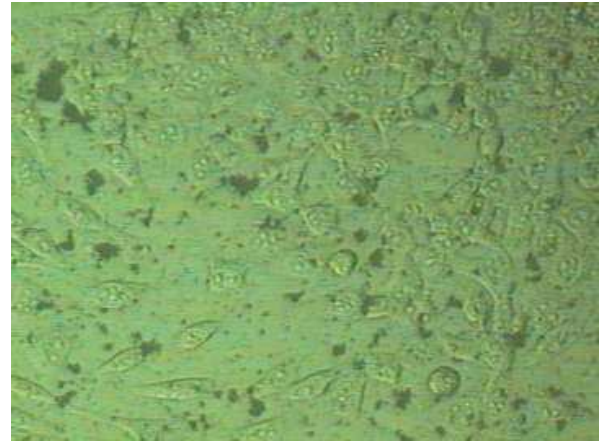

(b)

Fig. 18. (a) and (b). Ceramic substrate after washing in HBSS and the fixation in glutaraldehide $25 \%$. Phase contrast microscopy (a) $20 \times$; (b) $40 \times$.

One may see cellular groups attached to the piezoelectric wafer but without forming a continuous layer. Finally, the surface of the ceramic wafer was treated for 4 min with trypsin $\left(5 \mathrm{ml} / 3^{\circ} \mathrm{C}\right)$. Then, the wafer was washed down with HBSS and deionized water. The surface of the ceramic wafer after this operation is shown in Fig.19 (a) and (b). One may see, again, the cellular groups but they do not form a continuous layer.

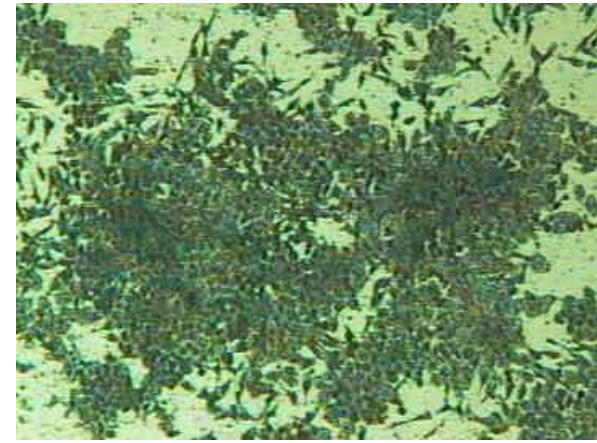

(a)

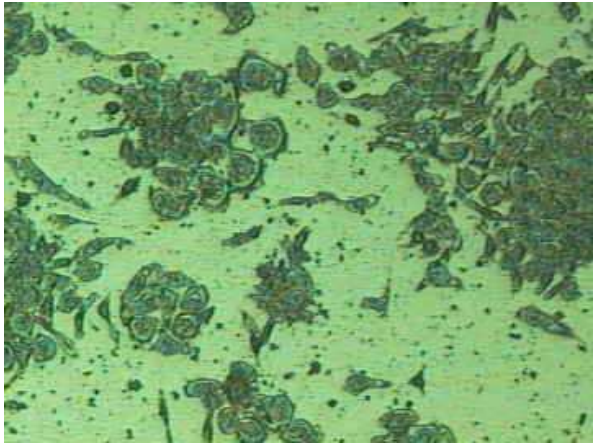

(b)

Fig. 19. (a) and (b). Aspect of the piezoceramic wafer surface after trypsin treatment. Phase contrast microscopy: (a) $-20 \times$; (b) $-40 \times$

At the same time, the two control Petri dishes show an abundant cellular development. 


\subsection{Influence of biological media on the piezoelectric ceramic substrate}

The initial texture of the mirror polished piezoelectric ceramic was investigated by an Atomic Force Microscope (AFM). The surface finish of the initial ceramic substrate is shown in Fig. 20 (a) and Fig 20 (b), in 2D and 3D rendering, for two scan area sizes: $20 \times 20 \mu \mathrm{m}^{2}$ and $2 \times 2 \mu \mathrm{m}^{2}$ respectively.

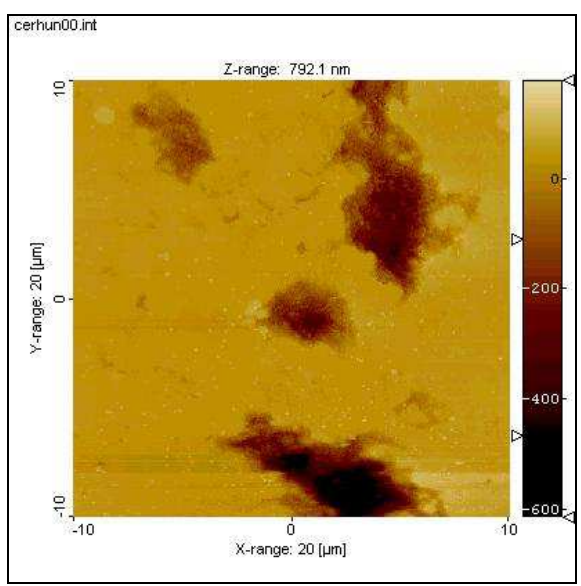

Fig. 20. (a) - 2D

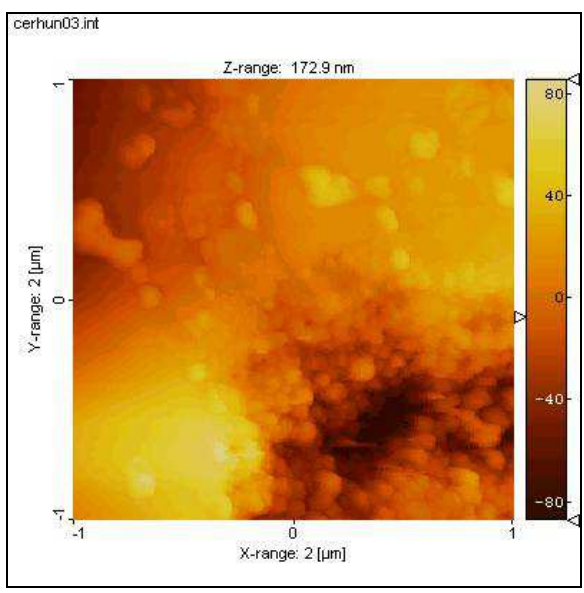

Fig. 20. (b) - 2D

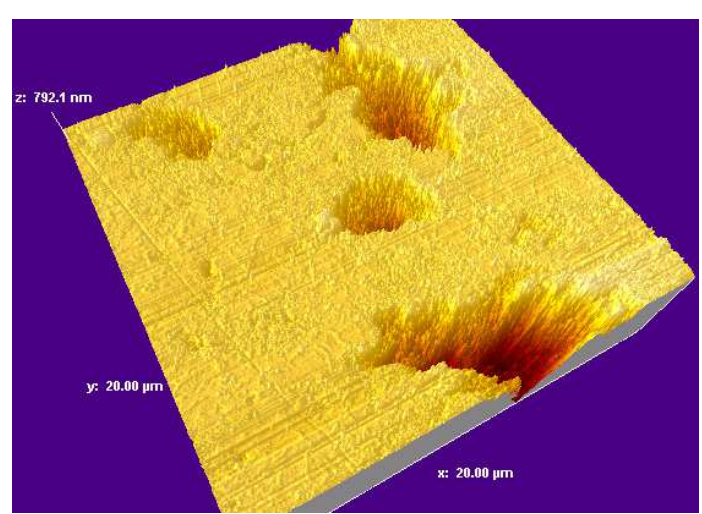

Fig. 20. (a) - 3D

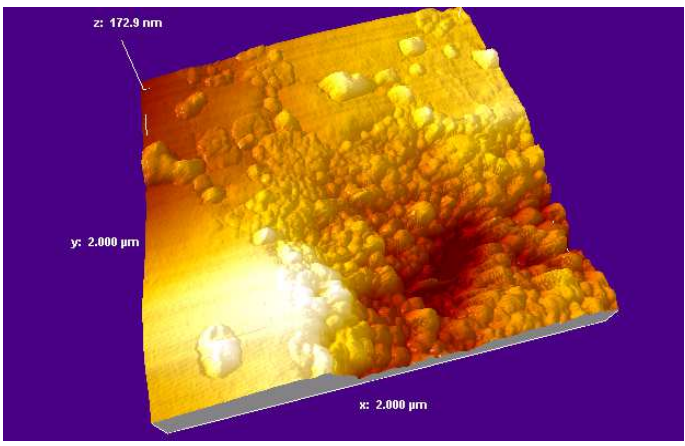

Fig. 20. (b) - 3D

Fig.20 (a) and (b). AFM recordings of the piezoceramic wafer surface roughness prior to the experiments, in 2D and 3D views. Scan area: (a) $-20 \times 20 \mu \mathrm{m}^{2}$; (b) $-2 \times 2 \mu \mathrm{m}^{2}$.

One can see in Fig.20 (a) that the surface is relatively smooth, yet featuring several holes of about $800 \mathrm{~nm}$ depths. One of these holes, together with its surrounding relatively flat area, is 
presented with higher resolution in Fig.20 (b). More measurements performed at different locations of the sample surface essentially revealed similar features as those shown in Fig.20. After the experiment, the ceramic wafer was cleaned and a new set of AFM measurements was performed. The results are shown in Fig.21 (a) and (b) for $20 \times 20 \mu \mathrm{m}^{2}$ and respectively $5 \times 5 \mu \mathrm{m}^{2}$ scan area, both in $2 \mathrm{D}$ and 3D views.

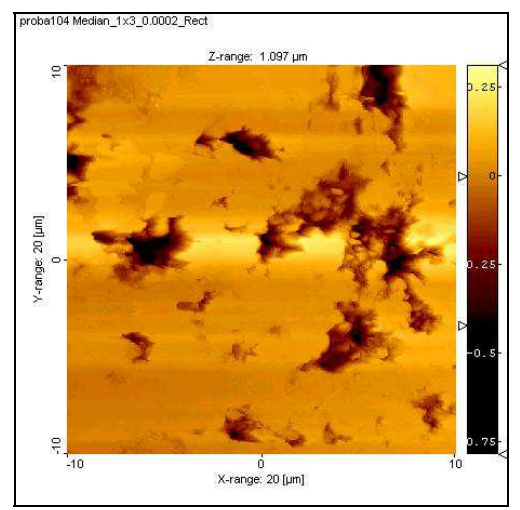

Fig. 21. (a) - 2D

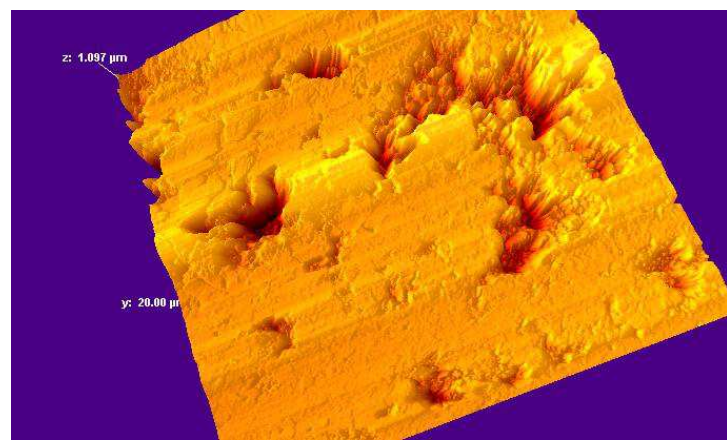

Fig. 21. (a) - 3D

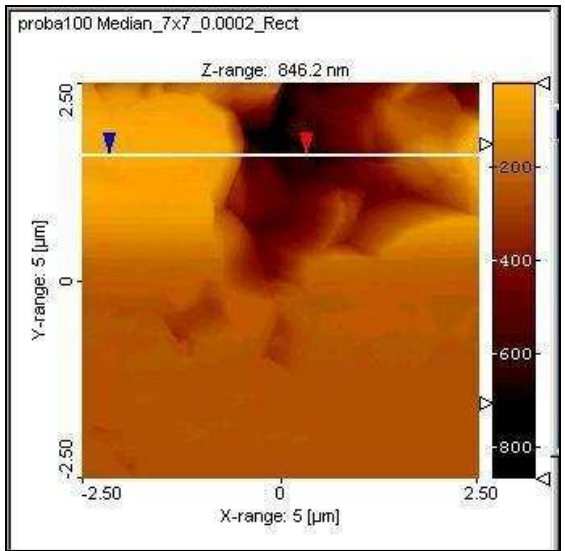

Fig. 21. (b) - 2D

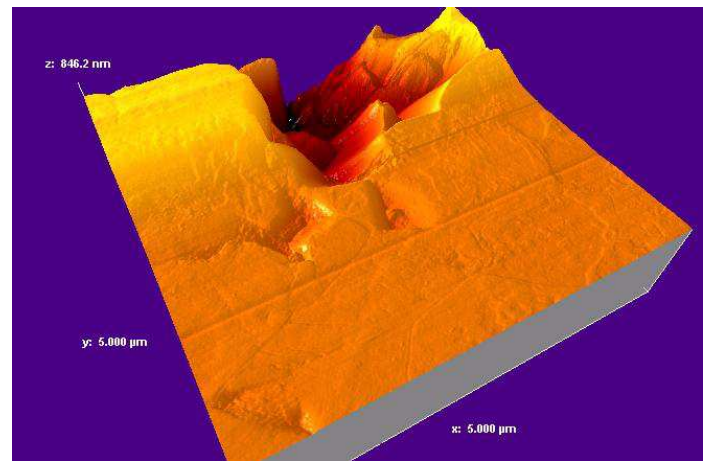

Fig. 21. (b) - 3D

Fig.21. AFM recordings of the piezoceramic wafer surface roughness after the experiments, in 2D and 3D views. Scan area: (a) $-20 \times 20 \mu \mathrm{m}^{2}$;

(b) $-5 \times 5 \mu \mathrm{m}^{2}$

As in the previous case, several additional scans were run, in different areas of the wafer, in order to check the uniformity of the surface morphology. Analogous to the previous case, at all locations of the ceramic surface, the morphological features were similar to those displayed in Fig. 21.

AFM measurements allowed to ascertain that the roughness of the ceramic wafer surface was essentially the same as it was prior to the experiments. 
A hole of about $750 \mathrm{~nm}$ depth could be seen in Fig.21 (b), comparable in size with the holes in Fig.20 (a). A profile of this hole is shown in Fig. 22, proving that the depth of the cavities featured in the initial surface topography (about $750 \mathrm{~nm}$ in this case) did not increase as a result of the action of cellular suspension and chemicals used in experiments.

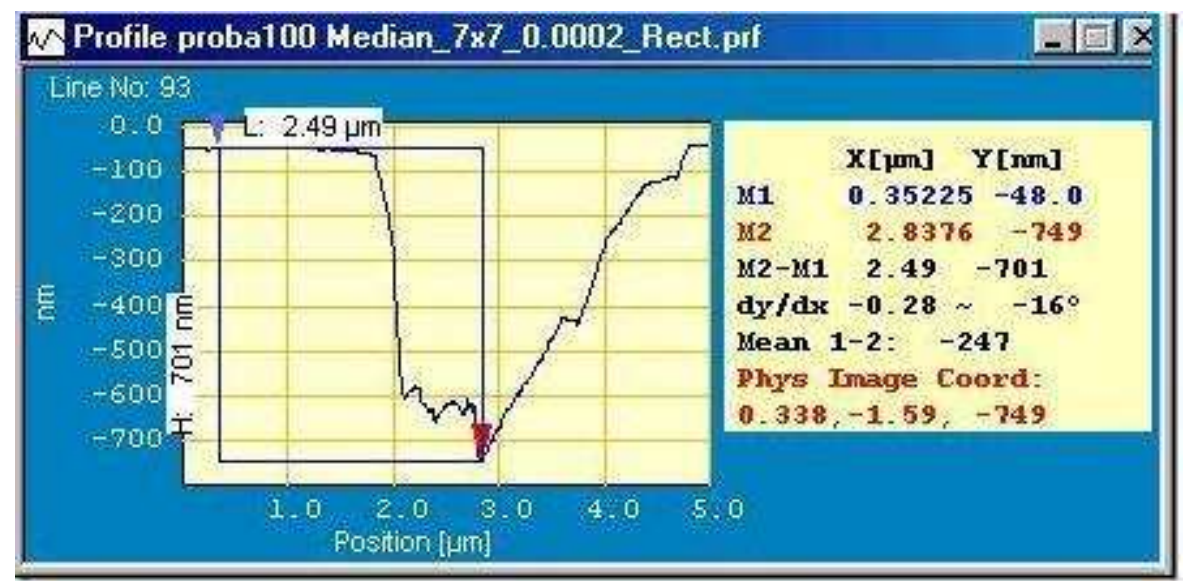

Fig. 22. Depth profile of the hole in Fig.21 (b) - 3D.

Therefore, the AFM investigations revealed that the texture of the ceramic wafer surface preserved its main features during the experiments.

As far as the cleaning of the piezoceramic wafer after the experiment is concerned, it was a more difficult task than expected. In the photo displayed in Fig.23, one may see the experimental ceramic wafer (left side) compared to a genuine one, of the same type and polished in the same manner (right side).

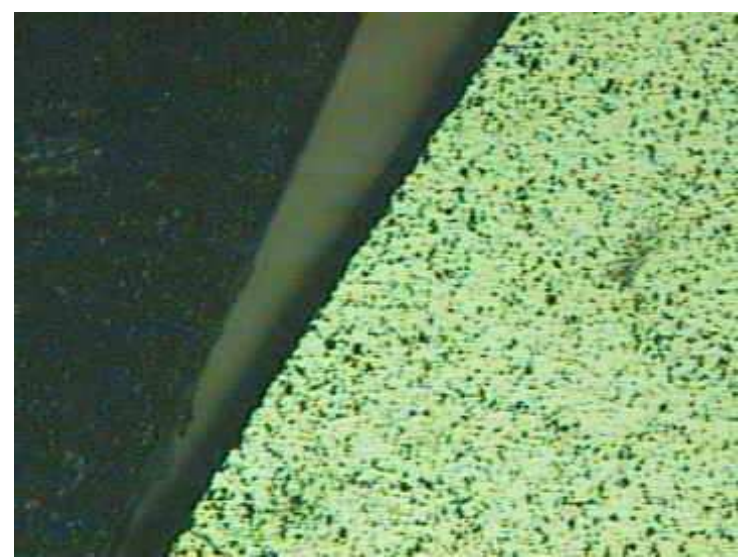

Fig. 23. Comparison between experimental ceramic wafer and a genuine one.

The photo was taken after a ceramic surface washing stage in a stream of deionized water. The adherence of the cellular remains on the ceramic surface is remarkable. Even after using 
a very strong mixture of oxidants there were still some cellular remains on the ceramic surface. The cellular remains could be totally removed only by re-polishing the ceramic wafer surface, but this operation could drastically damage the SAW interdigital transducers.

\subsection{Discussion on the biocompatibility between ceramic substrate and biologic medium}

In order to obtain a microfluidic micro-mixer for applications in medicine and biology, experiments were made on biocompatibility between piezoelectric ceramic and the aggressive medium consisting of a biological cellular suspension and the chemicals used. The objectives were to establish if this kind of ceramic substrate has an influence on the development of a cell population and reciprocal, if the action of the biological medium and chemicals could damage the surface of the ceramic wafer.

For the first objective, the growth of the cellular population was affected by the presence of the ceramic substrate. As one may see in Fig.17, on the $3^{\text {rd }}$ day of experiment the cells had difficulties to fix themselves and grow on the ceramic substrate. Even on the $4^{\text {th }}$ day, when the experiment ended, the cells failed to form a continuous layer over the whole ceramic surface (see Figs.18 and 19).

Regarding the second objective, the PZT ceramic surface was not affected. The substrate roughness and the surface porosity were not modified following the contact with the cell suspension and chemicals. As a negative aspect, the cellular remains (dead cells) on the wafer surface are rather difficult to clean out.

A method of solving this last problem may consist in coating the entire mixing surface with another material which is easy to clean, but this solution may reduce the mixing efficiency. In addition, the question of the biocompatibility is transferred from the ceramic-biological medium system to the ceramic protection layer-biological medium system.

\section{References}

Blank D.H.A., Moisin A.M., Addemir O., Andronescu E., Sajin G., Enescu V., Balazs L., Sztaniszlav A., Ferenc J., Sugurovas V., (2005). Ceramic Substrate with Controlled Piezoelectric Properties for Surface Acoustic Wave Applications. NATO SfP Project 974130 Final Report, 2005.

Cai, W.W., Mao, J.H., Chow, C.W., Damani, S., Balmain, A., Bradley, A., (2002). Genomewide detection of chromosomal imbalances in tumors using BAC microarrays, Nature Biotech. 20(2002), pp. 393-396, ISSN: 1087-0156.

Hames, H.D., Higgins, S.J., (1990). Nucleic acid hybridization - a practical approach, IRL Press, Oxford, Washington DC. ISBN: 9780947946616.

Jaffe, B., Cook, W.R., Jaffe, H., (1971). Piezoelectric Ceramics, Academic Press, London, New York, 1971. DOI: 10.1016/0022-460X(72)90684-0.

Kong, L.B., Ma, J., Zhu, W., Tan, O.K., (2002). Lead zirconate titanate ceramics achieved by reaction sintering of $\mathrm{PbO}$ and high-energy ball milled $(\mathrm{ZrTi}) \mathrm{O}_{2}$ nanosized powders Journal of Alloys and Compounds 236, 2002, p.242, ISSN: 0925-8388.

Moisin, A.M, Dumitru, A.I., Pasuk, I., Stoian, G., (2006). Structural investigation of PMN-PT system, Journal of Optoelectronics and Advanced Materials 8 (2), 2006, p.555, ISSN: 1454-4164.

Morgan D., (2007). Surface Acoustic Wave Filters, Elsevier, ISBN: 978-0-1237-2537-0. 
Pollack, J.R., Perou, C., Alizahdeh, A., Eisen, M., Pergamenschikov, A., Wiliams, C., Jeffrey, S., Botstein, D., Brown, P., (1999). Genome-wide analysis of DNA copy-number changes using cDNA microarrays, Nat. Genetics 23(1999), pp.41-46, ISSN: 1061-4036.

Sajin, G., Moisin, A.M., Craciunoiu, F., Dumitru A.I., (2005). SAW Resonators on ceramics with controlled piezoelectric properties, Proceedings of the $28^{\text {th }}$ International Semiconductor Conference, CAS, Sinaia, Romania, 03 - 04 Oct., 2005, p. 95 - 98. ISBN 0-7803-9214-0.

Sajin G., Petrescu D., Sajin M., Craciunoiu F., Gavrila R., (2006). Testing the biocompatibility of the piezoelectric ceramics and biological media. Proceedings of the World Congress on Medical Physics and Biomedical Engineering "Imaging the Future Medicine", 27 August - 01 Sept. 2006, Seoul, Korea, pp. 3179 - 3182, ISBN 3-540-36839-6.

Setter, N., editor, (2002). Piezoelectric Materials in Devices, EPFL, Lausanne, ISBN: 2-9700346-0-3

Southern, E., Mir, K., Shchepinov, M., (1999). Molecular interactions on microarrays, Nat. Genetics (Suppl.), Vol. 21(1999), pp. 5-9, ISSN: 1061-4036.

Toegl, A., Kirchner, R., Gauer, C., Wixforth, A., (2003). Enhancing Results of Microarray Hybridizations Through Microagitation, Journal of Biomolecular Techniques, 14, Sept.2003, pp.197-204. 


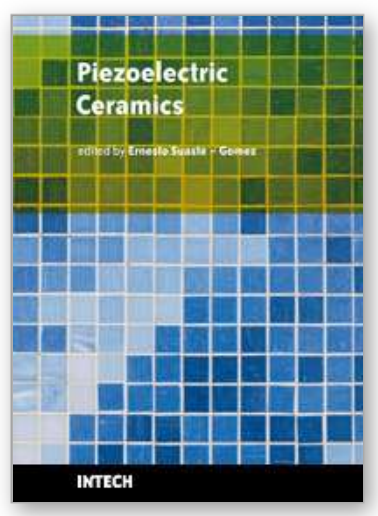

\author{
Piezoelectric Ceramics \\ Edited by Ernesto Suaste-Gomez
}

ISBN 978-953-307-122-0

Hard cover, 294 pages

Publisher Sciyo

Published online 05, October, 2010

Published in print edition October, 2010

This book reviews a big window of opportunity for piezoelectric ceramics, such as new materials, material combinations, structures, damages and porosity effects. In addition, applications of sensors, actuators, transducers for ultrasonic imaging, positioning systems, energy harvesting, biomedical and microelectronic devices are described. The book consists of fourteen chapters. The genetic algorithm is used for identification of RLC parameters in the equivalent electrical circuit of piezoelectric transducers. Concept and development perspectives for piezoelectric energy harvesting are described. The characterization of principal properties and advantages of a novel device called ceramic-controlled piezoelectric with a Pt wire implant is included. Biocompatibility studies between piezoelectric ceramic material and biological cell suspension are exposed. Thus, piezoelectric ceramics have been a very favorable solution as a consequence of its high energy density and the variety of fabrication techniques to obtain bulk or thin films devices. Finally, the readers will perceive a trend analysis and examine recent developments in different fields of applications of piezoelectric ceramics.

\title{
How to reference
}

In order to correctly reference this scholarly work, feel free to copy and paste the following:

Sajin M., Craciunoiu F., Moisin A.M., Dumitru A.I., Petrescu D., Raluca G., Bunea A.C., Sajin G.I. (2010). Piezoelectric Ceramic Applications: Micromixing in Biology and Medicine, Piezoelectric Ceramics, Ernesto Suaste-Gomez (Ed.), ISBN: 978-953-307-122-0, InTech, Available from:

http://www.intechopen.com/books/piezoelectric-ceramics/piezoelectric-ceramic-applications-micromixing-inbiology-and-medicine

\section{INTECH}

open science | open minds

\section{InTech Europe}

University Campus STeP Ri

Slavka Krautzeka 83/A

51000 Rijeka, Croatia

Phone: +385 (51) 770447

Fax: +385 (51) 686166

www.intechopen.com

\section{InTech China}

Unit 405, Office Block, Hotel Equatorial Shanghai

No.65, Yan An Road (West), Shanghai, 200040, China 中国上海市延安西路65号上海国际贵都大饭店办公楼405单元

Phone: +86-21-62489820

Fax: $+86-21-62489821$ 
(C) 2010 The Author(s). Licensee IntechOpen. This chapter is distributed under the terms of the Creative Commons Attribution-NonCommercialShareAlike-3.0 License, which permits use, distribution and reproduction for non-commercial purposes, provided the original is properly cited and derivative works building on this content are distributed under the same license. 